\title{
Early Diagnosis and Follow-Up of Spontaneous Heterotopic Pregnancy
}

\author{
Acko-Ohui E', Kouamé N'goran², Konan AN², Setcheou A², Lia Whiva Aubin ${ }^{3}$, N'goan-Domoua Anne-Marie' ${ }^{2}$ Konan AV ${ }^{2}$ \\ ${ }^{1}$ Radiology Department of Treichville University Hospital, Abidjan (Côte d'Ivoire), ${ }^{2}$ Radiology Department of Yopougon University Hospital, Abidjan (Côte d'Ivoire), \\ ${ }^{3}$ Obstetrics and Gynecology Department of Yamoussoukro Regional Hospital, Yamoussoukro. (Côte d'Ivoire).
}

\section{Abstract}

Heterotopic pregnancy is the coexistence of intrauterine pregnancy (IUP) and ectopic pregnancy (EP) in the same patient regardless of the location of the EP. It is a rare but not exceptional pathology whose diagnosis, based on ultrasound, is often difficult. This results in a late discovery involving the patient's vital prognosis. We report a case of a spontaneous heterotopic pregnancy that occurred in a 26-year-old patient, in whom early ultrasound diagnosis and early management helped to preserve the intrauterine pregnancy that was followed up to the eventual delivery of a eutrophic new-born in apparent good health. Our objective is to recall the existence of this pathology and to contribute to its early diagnosis through the proposal of 3 diagnostic keys.

Keywords: Heterotopic pregnancy, ectopic pregnancy, pathology of the first trimester of pregnancy.

Corresponding Author: Dr Kouame N'goran, Senior Lecturer, FIIB University-Abidjan (Côte d'Ivoire).

Received: August 2018

Accepted: September 2018

\section{Introduction}

Heterotopic pregnancy is the coexistence of intrauterine pregnancy (IUP) and ectopic pregnancy (EP) in the same patient regardless of the location of the EP. ${ }^{[1]}$ Its spontaneous nature, which is rare, ${ }^{[2]}$ is opposed to its propensity to be frequently observed during induced pregnancies or pregnancies linked to medically assisted procreation. However its early ultrasound diagnosis, a guarantee of efficient and effective management, is difficult. $^{[3]}$ The consequence is a late discovery of this pathology with life-threatening consequences for the patient. We report a case of spontaneous heterotopic pregnancy that occurred in a 26-year-old patient, in whom early diagnosis and early management helped to preserve the intrauterine pregnancy that was followed until the fullterm delivery of a eutrophic newborn in apparent good health. Our objective is to recall the existence of this pathology and to contribute to its early diagnosis through the proposal of 3 diagnostic keys.

\section{Case Report}

Ms. P.A.J, G3P2, aged 26, was referred to the radiology department of the University Hospital of Yopougon to perform an abdominopelvic ultrasound. The reason was excruciating abdominal-pelvic pain in a context of 2-month gestational amenorrhea without any notion of bleeding. A pelvic ultrasound performed a week earlier [Figure 1], on the basis of intense pelvic pain, had revealed an evolutionary twin dichoreal intrauterine pregnancy of 6 weeks of amenorrhea. Treatment with Spasfon ${ }^{\circledR}$ suppositories, Utrogestan ${ }^{\circledR}$ and ice bladder was instituted without success. Faced with the development and extension of pain throughout the abdomen, the gynecologist demanded that the ultrasound be performed at the University Hospital.

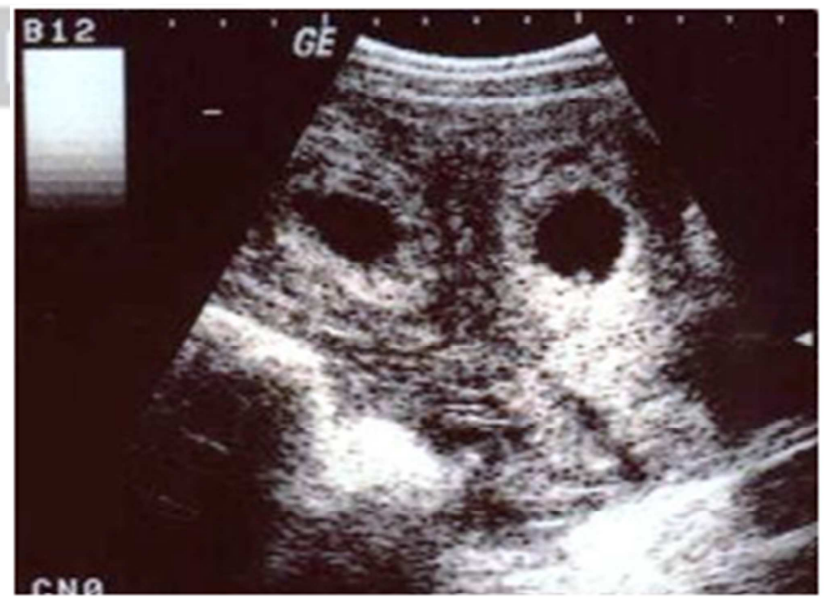

Figure 1: Pelvic ultrasound, performed at 6 weeks of amenorrhea in a 26-year-old patient concludes with twin pregnancy.

The ultrasound examination was performed in mode B by supra-pubic and endovaginal approach [Figure $2 \& 3$ ]. It highlighted 2 embryonated gestational sacs separated by a myometrium too thick to be a twin pregnancy. The endovaginal path showed an intrauterine sac and a right lateral uterine ectopic sac. Both sacs contained embryos, with a perceptible and regular cardiac activity, measuring 
10 and $11 \mathrm{~mm}$ crown-rump length respectively. This corresponded to a gestational age of 7 weeks of amenorrhea and 2 days. The myometrium was homogeneous and there was no intraperitoneal fluid effusion. We concluded that it was a non-ruptured heterotopic pregnancy. The patient underwent a laparotomy which confirmed the diagnosis [Figure 4]. The surgeons performed a subtotal right salpingectomy. Intrauterine pregnancy was preserved and monitored until the birth of a 3200-gram newborn whose Apgar score was 10/10.

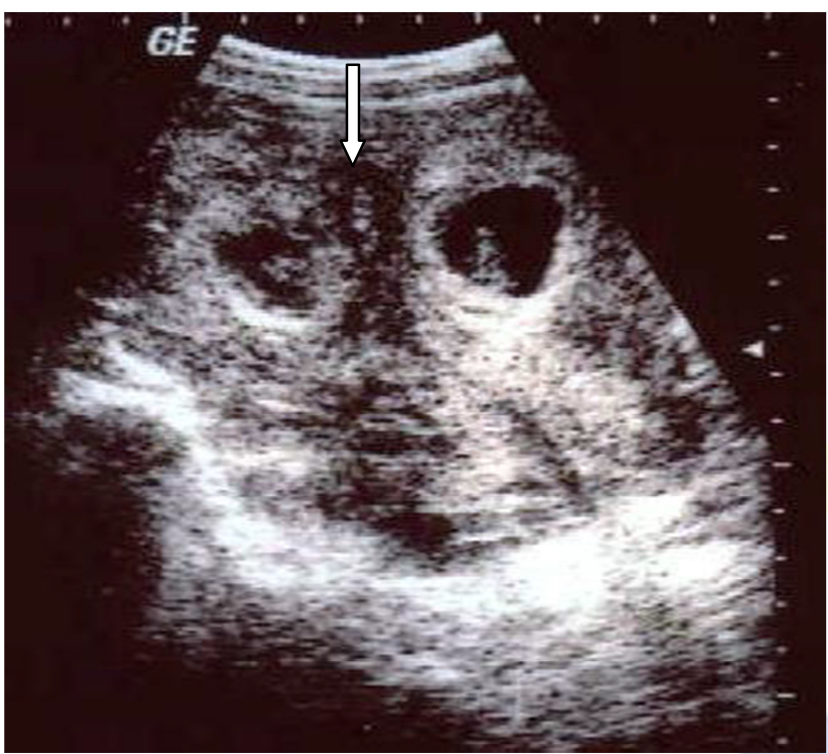

Figure 2: Same patient. Pelvic ultrasound performed at 7weeks of amenorrhea by suprapubic approach showing 2apparently intrauterine gestational sacs. Note the presence of a large gap between both sacs (white arrow) making doubt the intrauterine situation of both sacs.

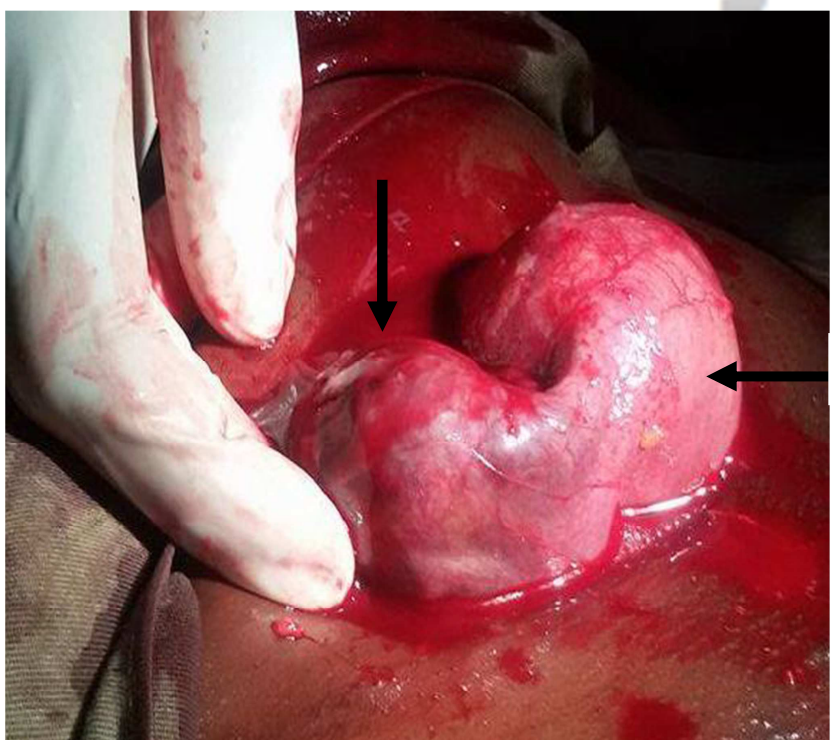

Figure 3 :Same patient. Laparotomy confirming heterotopic pregnancy. Ampullary gestational sac (vertical arrow) and gravid uterus (horizontal arrow).

\section{Discussion}

\section{Comment}

According to Bright, ${ }^{[4]}$ heterotopic pregnancy, which was described for the first time by Duvernet in 1708, is rare but not exceptional. Its frequency is nowadays increasing because of medically assisted procreation (at the origin of induced heterotopic pregnancy) and sexually transmitted infections responsible for spontaneous heterotopic pregnancy as shown in our patient. It concerns a young population whose age varies between 20 and 35 years. Our patient was 26 years old. According to Amagada, ${ }^{[3]}$ the most frequently encountered clinical signs are those of the ectopic pregnancy (EP) (amenorrhea triad, pelvic pain, and metrorrhagia). But most often, especially in our countries, the diagnosis is made at the stage of peritoneal irritation syndrome or hemorrhagic chock because of late consultations. Cases of perioperative diagnosis have been observed and other times the diagnosis was made at autopsy. ${ }^{[5]}$ This is to say all the diagnostic difficulty despite the advent of ultrasound which sometimes doesn't visualize concomitantly one or the other of both pregnancies that are the EP and the IUP. These sonographic diagnostic errors are often related to the lack of attention of sonographers who do not sufficiently assess the perioperative environment of an intrauterine pregnancy or to precipitation due to a heavy workload. Many sonographers are not sufficiently equipped and a confusion between an intra-uterine gestational sac and a gestational pseudo-sac leads to a misdiagnosis. According to Morin and Ardaens, ${ }^{[6,7]}$ the gestational sac is differentiated from the pseudosac by the existence of two crowns (the thickened caduceus and the chorionic cavity which is composed of an anechoic fluid body surrounded by an echogenic ring, which represents trophoblasts and the decidual reaction) while the pseudo-sac consists of a single endometrial crown. The use of color Doppler could also help to make the difference between the intrauterine egg sac and the pseudo-sac. Indeed, according to Dillon, ${ }^{[8]}$ the pseudo-sac is not surrounded by any arterial or venous type of flow whereas the demonstration of an arterial or venous flow with circulatory speeds greater than $20 \mathrm{~cm} / \mathrm{s}$ would affirm the ovular nature of the picture. Other of causes of diagnostic error may exist. They may be related to the particular and misleading presentation of heterotopic pregnancy. In our case, heterotopic pregnancy mistakenly simulated a twin pregnancy. The large thickness of the myometrium separating both gestational bags caught our attention and led us to resort to the endovaginal approach to correct the diagnosis. The right ampullary situation of the $\mathrm{EP}$, observed in our case, is very frequently described in the literature. $^{[9]}$ There was no rupture and therefore no hemoperitoneum. This is not often the case in the literature where late stages of discovery are the prerogative of this affection. $^{[4-7]}$ Our diagnosis was performed at 7 weeks of amenorrhea and would have been at an earlier stage if the first ultrasound had not been performed in a peripheral health center by non-experienced practitioners.

Surgical management is the mode of treatment of this 
condition. It can be done by laparoscopy approach or open surgery. Laparoscopy being the current reference with a diagnostic confirmation part preceding treatment. ${ }^{[10]}$ Open surgery was practiced in our case because our technical platform imposed it on us. It successfully consisted in performing a subtotal right salpingectomy. The outcome was favorable with ultrasound surveillance of intrauterine pregnancy until term. This surgical technique was also practiced by Traoré in Mali who performed, ${ }^{[9]}$ after laparotomy, a partial salpingectomy respecting the interstitial portion associated with minimal uterine manipulation. In our case, uterine pregnancy came to term with the birth of a eutrophic newborn and in apparent good health. According to Diallo, ${ }^{[10]}$ the live birth rate in case of heterotopic pregnancy is $64 \%$.

\section{Conclusion}

Although uncommon, heterotopic pregnancy exists and must be diagnosed early in order to preserve the patient's life and intrauterine pregnancy. Ultrasound is the dedicated paraclinical examination whose effectiveness requires 3 keys:

1. Systematically and thoroughly examine the periuterine environment in case of IUP or the uterine cavitary line in case of EP.

2. Avoid any confusion between intrauterine gestational sac and gestational pseudosac related to the decidualized endometrium.

3. Resort, at the slightest doubt, to the endovaginal approach, especially in the case of apparently twin pregnancy, with a significant separation between both sacs.

\section{References}

1. Chandra PC, Schiavello HJ, Briggs SL, Samuels JD. Heterotopic pregnancy with term delivery after rupture of a first- trimester tubal pregnancy. A case report. J Reprod Med 1999 ; 44(6): 556-8.

2. Rabarikoto H F, Randriamahavonjy R, Rabetsimamanga L A Z, Tovone T M M, Samison L H, Andrianampanalinarivo H R. Deux cas de grossesses hétérotopiques spontanées au Centre Hospitalier de Soavinandriana Antananarivo. Revue d'Anesthésie-Réanimation et de Médecine d'Urgence $2010 ; 2(2): 21-4$.

3. Amagada JO, Vine SJ. Spontaneous hetrotopic pregnancy remains a diagnostic enigma. J obstet Gynaecol 2005 ; 25 (1) : 72-3

4. Bright DA, Gaupp FB. Heterotopic pregnancy; a reevaluation. J Am Board Fam Practice $1990 ; 3: 125-8$

5. Aguemon CT, Denakpo J, Hounkpatin B, Tossa LB, Adisso S, Sacca J et al. Grossesse hétérotopique à la clinique Universitaire de Gynécologies et d'Obstétrique du Centre National Hospitalier et Universitaire Hubert Koutoukou Maga du Bénin : à propos d'un cas de grossesse quadruple ; 3 foetus intra utérins et 1 foetus abdominal. Pan Afr Med J. 2015; 20 : 394

6. Morin L, Van den Hof M. Évaluation échographique des complications liées à la grossesse pendant le premier trimestre. J Obstet Gynaecol Can $2005 ; 27$ (6) : 586-91

7. Ardaens Y, Guérin B, Perrot N, Legoeff F. Apport de l'échographie dans le diagnostic de la grossesse extra-utérine. Journal de Gynécologie Obstétrique et Biologie de la Reproduction 2003 ; 32(S7) : 28-38

8. Dillon EH, Feyock AL, Taylor KJ. Pseudogestational sacs : Doppler US differentiation from normal or abnormal intra-uterine pregnancies. Radiology 1990 ; $176: 359-64$

9. Traore Y, Teguete I, Thera AT, Mulbah JK, Kane F, Mounkoro N, et al. Association grossesse extra-utérine et intra utérine : à propos de 3 cas. Mali médical 2006 ; 11 (6) : 35-38

10. Diallo D, Aubard Y, Piver P, Baudet JH. Grossesse hétérotopique : à propos de 5 cas et revue de la littérature. J Gynecol obstet Biol Reprod. 2000; 29(2) :131-141.

Copyright: (๑) the author(s), publisher. Asian Journal of Medical Radiological Research is an Official Publication of "Society for Health Care \& Research Development". It is an open-access article distributed under the terms of the Creative Commons Attribution Non-Commercial License, which permits unrestricted non-commercial use, distribution, and reproduction in any medium, provided the original work is properly cited.

How to cite this article: Acko-Ohui EV, Kouamé N, Konan AN, Setcheou A, Lia WA, N'goan-Domoua AM, Konan AV. Early Diagnosis and Follow-Up of Spontaneous Heterotopic Pregnancy. Asian J. Med. Radiol. Res. 2018;6(1):12-14.

DOI: dx.doi.org/10.21276/ajmrr.2018.6.1.4 